\title{
BMJ Open Quality Appropriate CT cervical spine utilisation in the emergency department
}

\author{
Mark Baker, ${ }^{1}$ Cassie Jaeger (1) ,, Carol Hafley, ${ }^{3}$ James Waymack ${ }^{1}$
}

To cite: Baker $M$, Jaeger $C$, Hafley C, et al. Appropriate CT cervical spine utilisation in the emergency department. BMJ Open Quality 2020;9:e000844. doi:10.1136/ bmjoq-2019-000844

Received 2 October 2019 Revised 30 July 2020 Accepted 18 September 2020
Check for updates

(c) Author(s) (or their employer(s)) 2020. Re-use permitted under CC BY-NC. No commercial re-use. See rights and permissions. Published by BMJ.

${ }^{1}$ Department of Emergency Medicine, Southern Illinois University School of Medicine, Springfield, Illinois, USA ${ }^{2}$ Department of Operations Improvement, Memorial Health System, Springfield, Illinois, USA ${ }^{3}$ Midwest Healthcare Quality Alliance, Memorial Health System, Springfield, Illinois, USA

Correspondence to

Dr Cassie Jaeger;

Hawk.Cassie@mhsil.com

\begin{abstract}
Introduction Over 40000 CT scans are performed in our emergency department (ED) annually and utilisation is over $80 \%$ capacity. Improving medical appropriateness of CT scans may reduce total number of scans, time, cost and radiation exposure.

Methods Lean Six Sigma methodology was used to improve the process. A National Emergency X-Radiography Utilisation Study (NEXUS)-based PowerForm was implemented in the electronic health record and providers were educated on the criteria.

Results The rate of potentially medically inappropriate CT C-spine scans decreased from $45 \%(19 / 42)$ to $22 \%(90 / 403)$ (two-proportion test, $\mathrm{p}=0.002)$. After the intervention, there was no longer a difference between midlevel providers and physicians in the rate of medically inappropriate orders (19\% vs 22\%) (two-proportion test, $\mathrm{p}=0.850)$ compared with that before the intervention $(56 \%$ vs $31 \%$ ) (two-proportion test, $p<0.01$ ). Overall rates of CT C-spine scans ordered decreased from 69.3 to 62.6/week (t-test, $p=0.019$ ).

Conclusion A validated clinical decision-making tool implemented into the medical record can improve quality of care. This study lays a foundation for other imaging studies with validated support tools with similar potential improvements.
\end{abstract}

\section{INTRODUCTION}

Over 40000 CT scans are performed annually at our hospital for approximately 75000 emergency department (ED) patient visits. The rate of CT scans is above the national average, which ranges from $11 \%$ to $24.6 \% .{ }^{1} \mathrm{It}$ is also concerning that the CT scan utilisation rate is significantly higher than comparable hospitals, with a study from Virginia Tech demonstrating a $23.8 \%$ utilisation rate. ${ }^{2}$ Our institution is a level 1 trauma centre, comprehensive stroke centre and a regional tertiary care centre. When comparing to similar hospital systems, the CT utilisation rate is still high. ${ }^{2}$ The data raised concerns that there may have been a significant amount of unnecessary CT scans ordered in the ED.

Improving the quality and efficiency of the healthcare system is becoming increasingly important. Ensuring that CT scans are appropriately ordered has significant impact on the quality of care delivered to patients. Advanced diagnostic studies such as CT scans have an associated high cost to the patient. ${ }^{3}$ Obtaining CT scans also increases the average length of stay for patients in the ED. ${ }^{4}$ ED crowding is a national problem and has recently made its way back into the national spotlight. ${ }^{5}$ Efforts to reduce length of stay are important to help with this problem. Aside from the economic reasons to ensure medical appropriateness of CT scans being ordered, another reason to reduce unnecessary scans is reduction in radiation dose exposure, which averages 6.2 millisievert $(\mathrm{mSV})$ per person in the USA annually from natural and medical sources. ${ }^{6}$ Cervical spine CT scans expose patients to between 1 and $5 \mathrm{mSv}$ of radiation. ${ }^{7}$ It is generally accepted that exposure to doses $>100 \mathrm{mSv}$ increases risk for developing cancer. ${ }^{8}$ Reducing the number of medically inappropriate CT scans is an essential component of improving quality of patient care, as this has been a focus of the Choosing Wisely Campaign for Emergency Medicine. ${ }^{10-12}$

Cervical spine injuries are concerning to physicians because of the high morbidity involved. ${ }^{13}$ The prevalence of cervical spine injury ranges from $2.8 \%$ in alert patients to $7.7 \%$ in altered patients who are unevaluable. ${ }^{14}$ This prevalence is certainly not negligible given the morbidity associated with these injuries. ${ }^{13}$ Cervical spine injuries occur along a spectrum from whiplash, which has very little morbidity associated with it, to ligamentous injuries, a variety of fractures, to spinal cord injuries which can have not only morbidity but associated mortality as well. ${ }^{13}$ It is difficult to differentiate between these injuries by only the patient history. ${ }^{15}$ However, using a thorough physical examination and, when appropriate, medical imaging, providers can accurately diagnose cervical spine injuries and provide the necessary care to mitigate preventable morbidity and mortality. ${ }^{15} 16$

Diagnostic imaging has significantly changed the management of patients with potential cervical spine imaging. ${ }^{17}$ Cervical spine radiographs identify most fractures but are largely unable to identify ligamentous injury or spinal cord injury. ${ }^{18} 19$ 
High-resolution CT scans, such as the 128 slice CT scanner at our institution, provide excellent sensitivity and specificity of skeletal injuries of the cervical spine and have demonstrated ability to even diagnose severe ligamentous injury. ${ }^{20}{ }^{21} \mathrm{CT}$ still lacks the power to diagnose spinal cord injury. MRI provides the best sensitivity and specificity for soft tissue injury, including ligaments, muscles and the spinal cord. ${ }^{22}{ }^{23}$ However, not all medical centres are able to offer MRI. MRI is expensive and even more time consuming which would increase length of stay of patients if it became routine practice to obtain these images in the ED. The clinician needs to weigh the risks, including cost, time and radiation exposure, of each of the imaging modalities to determine what the most appropriate diagnostic test is, if any, to order for the patient. ${ }^{17}$

Clinical decision tools were developed to assist providers in determining which patients need cervical spine imaging of any kind after a neck injury. The National Emergency X-Radiology Utilisation (NEXUS) group performed a study in 1998 demonstrating 99.6\% sensitivity and $90.7 \%$ specificity for cervical spine injuries. Five criteria must be met in order to clinically clear the cervical spine without obtaining any imaging studies. The patient must not have posterior midline tenderness, must not have any evidence of intoxication, must demonstrate normal levels of alertness, must not have any neurological deficit and must have a painful distracting injury. ${ }^{16}$ This study has been validated many times and remains one of the two primary clinical decision tools regarding blunt cervical spine trauma. ${ }^{24-27}$

The Canadian C-Spine Rule is another validated clinical decision support tool. ${ }^{24} 28$ The American College of Radiology (ACR) recommendations also support the statement that it would be medically inappropriate to order a CT C-spine on a patient that is determined to be low risk by NEXUS criteria. ${ }^{29}$ Currently, reimbursement is not linked to ACR ratings. However, there is impending regulation that may affect reimbursement from Medicare patients if ACR criteria are not met. ${ }^{30}$

The ACR has developed criteria to rate the medical appropriateness of diagnostic imaging studies for given complaints. The rating system is a numerical system, with 9 being strongly supported and 1 being strongly recommended against by the ACR. A CT scan of the cervical spine without intravenous contrast is rated 9 if the patient fails to pass the NEXUS criteria or Canadian C-Spine Rule and rated 1 if either have been met.

Other centres have performed studies analysing this same problem, suggesting that strictly using the NEXUS criteria may reduce CT cervical spine imaging studies by up to $20 \% .^{31-34}$

Strategies to reduce inappropriate imaging studies include teaching sessions, email or reminder letters with guidelines, report cards that include provider ordering practices, and computerised decision support. ${ }^{35}$ Stiell et al implemented real-time reminders of the Canadian C-Spine Rules on radiology requisitions in addition to education and policy changes and reported a $12.8 \%$ reduction in imaging studies for hospitals that implemented the changes. ${ }^{36}$ Goergen et al reported a $9.7 \%$ decrease in C-spine studies after implementation of pocket card reminders with the guidelines, teaching sessions and optional use of computerised decision support software. Of the $40 \%$ of patients that were managed by the computerised decision support tool, $36 \%$ were not appropriate for C-spine imaging. ${ }^{37}$

This project was part of a quality improvement initiative by our institution. We hypothesised that improving the rate of medical imaging appropriateness will increase the quality of care being provided to patients in the ED. The purpose of this study was to reduce the number of medically inappropriate CT scans of the cervical spine by $30 \%$.

\section{METHODS}

The project was reviewed by the local institutional review board. It was determined that the project was considered non-human subjects research. Patients or the public were not involved in the design, or conduct, or reporting or dissemination plans of our research. All non-trauma ED patients over 18 years of age met the inclusion criteria. Patients with trauma were excluded as they have a different protocol for ordering studies. Project team members included an ED and imaging manager, ED medical director, physician and resident, a nurse practitioner and quality nurse.

Our hospital uses Lean Six Sigma methodology for continuous improvement to decrease defect rates, variation and to eliminate non-value-added steps. Although initially implemented in manufacturing, General Electric and Toyota, use of Lean Six Sigma tools can effectively be used in service industries, including healthcare. ${ }^{38-43}$ The Lean Six Sigma approach is embedded within the organisation, with nearly $50 \%$ of the workforce exposed to some level of Lean Six Sigma training. The methodology was used to guide the team through each of the key decision points. In the define phase, development of a problem statement helped the team clarify the issue and determine a measurable outcome. Scoping was used to specify inclusion and exclusion criteria. Supplier, input, process, output, customer (SIPOC) analysis was used to define start and stop points, inputs needed for the process, and identified customers whose feedback on the process was needed. Collection of voice of the customer identified what is critical to have a process that is safe, timely, efficient, effective and patient centred. Those requirements identified what outcomes should be measured in the data collection plan.

In the measure phase, process mapping organised the tasks completed from different disciplines into one overall process. Measures were defined in a data collection plan and included number of CT, C-spine and face scans that were not medically appropriate as determined by physician chart review. The data collection plan also included segmentation of medically appropriate scans ordered by midlevels. 
An initial chart review of a random sample of 132 CT scans of all types revealed that $33 \%$ were potentially medically inappropriate. Common themes from the initial chart review were poor documentation of the NEXUS criteria, no documentation of neck pain and that a CT scan may have been selected over an MRI due to availability in some instances. The fast-track area in the ED, mainly staffed by midlevel providers, was also identified as a potential area of concern for high rates of potentially medically inappropriate scans. The initial chart review did not have a high enough number of scans to show a statistical difference based on ordering provider training, scan type or patient acuity, therefore additional chart reviews were completed.

Further chart reviews focused primarily on CT scans of the cervical spine and CT scans of the face, as these stood out to the reviewing providers as potential areas of concern and had potential for meaningful intervention. An additional 29 CT cervical spine and $30 \mathrm{CT}$ facial bones were reviewed. Altogether, $45 \%$ of the $42 \mathrm{C}$-spine studies were determined to be potentially medically inappropriate. Only 25 studies ordered by midlevel providers were in this point in the chart reviews. An additional 46 CT scans ordered by midlevel providers were reviewed to allow for better statistical power. Midlevel providers' orders were potentially medically inappropriate $56 \%(40 / 71)$ of the time relative to $31 \%(52 / 166)$ of the orders by attending physicians (two-proportion test, $\mathrm{p}<0.01$ ).

In the analyse and improve phases, tools used by the Lean Six Sigma process were used to determine the root cause of the problem, compare potential solutions and evaluate risk of process changes. ${ }^{44} \mathrm{~A}$ five why's analysis was used to ask why medically inappropriate scans are completed and identified absence of supportive documentation. Through cause mapping, the project team discovered that documentation reason for imaging studies was poor potentially due to lack of clinical decision support, documentation not being pre-built into an electronic template and the time it takes to document.

An affinity diagram was created to organise potential solutions for documentation, education and culture. Solutions discussed included education on appropriate C-spine imaging, a refresh on NEXUS and Canadian C-spine criteria and sharing literature. Documentation solutions discussed included building the criteria into the EHR through templates and required fields, updating order sets to include imaging reasons, NEXUS criteria and required criteria. The team also discussed CT staff and nurses following up with the ordering physician when criteria was not met.

An impact effort matrix was used to determine the feasibility of potential improvements. Improvements with a lower effort to implement that had a high potential impact included building ACR select criteria into physician document management, building NEXUS rules into medical decision-making templates, education on appropriate documentation and a refresh on NEXUS criteria.

Due to billing requirements and radiology requiring additional information to support imaging studies, building criteria and rules into templates was not feasible. The team decided to implement a NEXUSbased PowerForm (figure 1). Future state process mapping helped the team organise the process change

\section{PowerForm}

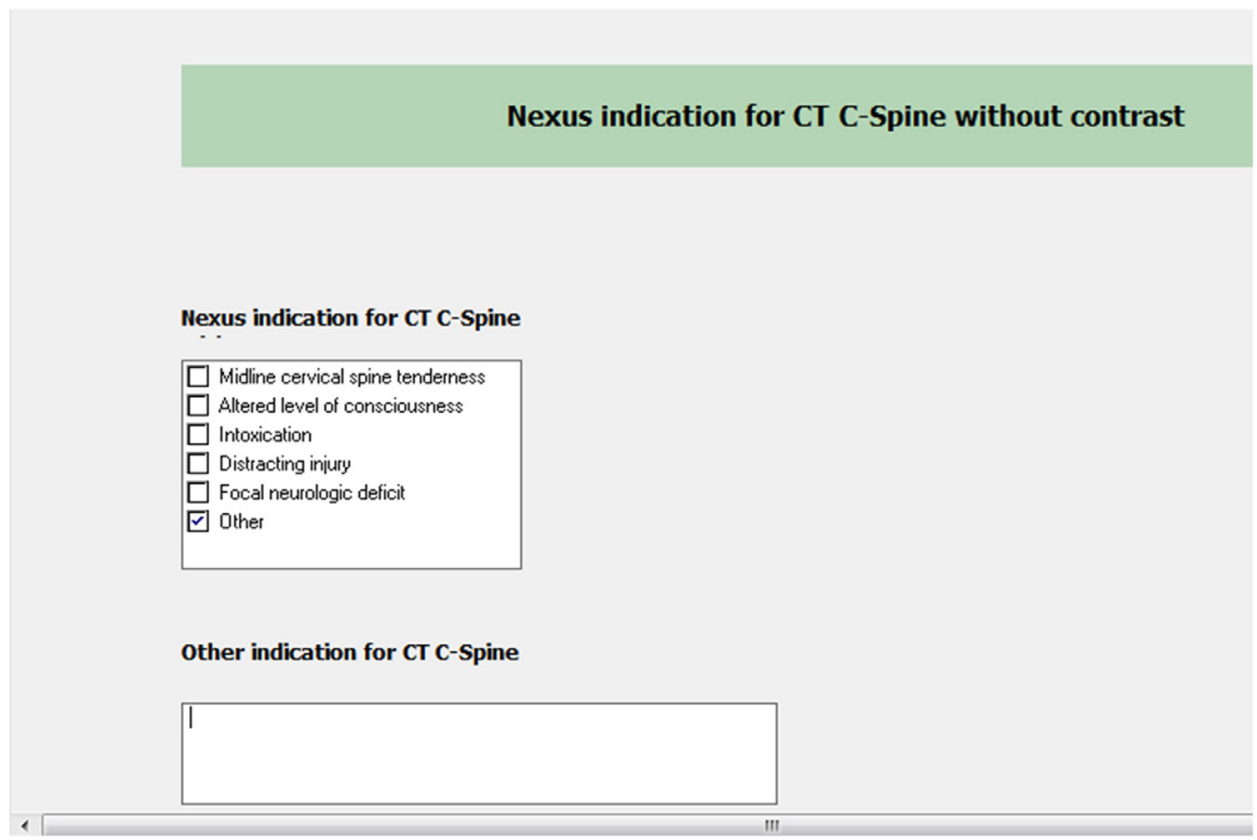

Figure 1 Screenshot of the PowerForm implemented into the medical record with NEXUS Criteria indications for CT C-spine orders. If 'other' was chosen, further details could be added in the free text box below the indication checklist. 
interventions and identify potential gaps. A rollout plan was developed to assign tasks, resources needed and a timeline. The control plan helped determine what monitoring was needed in order to keep the improvements sustained over time.

A NEXUS-based PowerForm was designed and implemented (figure 1). A lecture was prepared by two emergency medicine residents involved in the project. The lecture included information about the number of CT scans being ordered at the study site compared with similar sites, the results from the initial chart review, the NEXUS criteria including the validation studies and information about the PowerForm that was created. This was presented to the emergency medicine residents during their weekly conference. It was sent to all attending physicians and discussed at the monthly physician group meeting. It was also added into the mandatory educational training for the midlevel providers. All providers had access to the educational material. Prior to implementing the PowerForm, informational flyers were also posted at provider workstations. In-person education was performed over the first few days of the go-live period by rounding through the department and answering any questions about the study or PowerForm.

After the intervention, 403 CT C-spine orders were consecutively analysed for NEXUS compliance. Data analysis was completed using two-sample t-test to compare weekly CT utilisation pre-intervention and post-intervention. Two-proportion test was used to determine ordering differences between providers and the percent of appropriate scans pre-intervention and post-intervention. All statistical tests were performed using Minitab V.18.1. A $p$ value of $<0.05$ was considered statistically significant.

\section{RESULTS}

CT C-spine scans were potentially medically inappropriate $22 \%(90 / 403)$ of the time after the intervention based on PowerForm results, down from $45 \%$ (19/42) prior to intervention (two-proportion test; $\mathrm{p}=0.002$ ) (figure 2). The midlevel and attending physician rates of potentially medically inappropriate orders were $19 \%$ and $22 \%$, respectively (two-proportion test, $\mathrm{p}=0.850$ ), no longer displaying a difference between the providers ordering the test. CT C-spine scans ordered each week decreased from 69.3 to 62.6 (two sample t-test, $\mathrm{p}=0.019$ ) (figure 3 ). ED patient volume was not significantly different preintervention and post-intervention.

\section{DISCUSSION}

The overall number of CT C-spine scans was reduced by over the $30 \%$ project target. CT reduction was achieved through improving medical appropriateness of the orders and reducing variability between providers. Cost reductions and length of stay were not specifically evaluated in the project, but a reduction in CT scans may correlate to improvements in these areas as well. The interventions
Percent of Medically Appropriate CT Scans
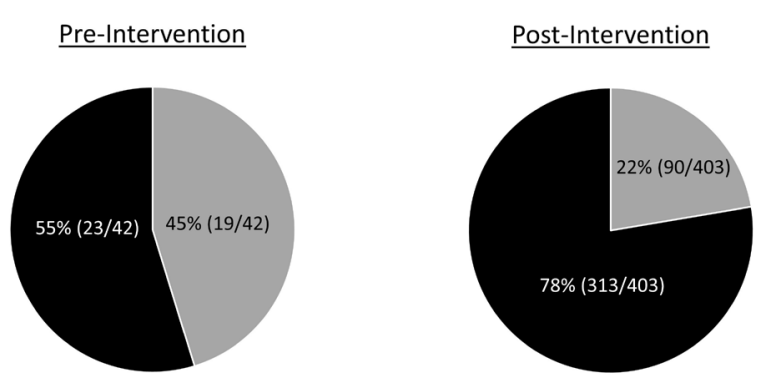

- Medically Appropriate

Medically Inappropriate

Figure 2 Medically appropriate CT scans before and after intervention. Chart reviews were used to determine appropriateness pre-intervention. Post-intervention appropriateness was based on documented NEXUS criteria selection.

may be replicated to other imaging modalities or other diagnostic tests.

To maintain sustainability of improvements, a control plan was implemented to monitor the percent of CT scans with a documented reason as 'other'. If more than $25 \%$ of orders had a reason documented as 'other', then an emergency medicine physician would complete a chart review and follow-up with 1:1 consultations with providers as needed if trends in ordering practice were identified.

Variability between providers in ordering diagnostic tests leads to poorer quality of care and inefficiencies in the medical system. The project identified a difference between midlevel and attending physicians prior to the intervention. When analysing this difference in conjunction with partners representing the group of midlevels, it was found that a knowledge deficit was likely behind this variance. The nurse practitioners and physician assistants were eager to improve their practice and incorporate clinical decision tools to make their practice not only more medically appropriate but also more efficient. After they incorporated the lecture into their continued education curriculum and the PowerForm was implemented into the medical record, the difference between attending physicians and midlevel providers was eliminated. Although not statistically significant, the trend in medically appropriate orders by midlevel providers was higher than attending physicians after the intervention. Reducing variability between providers allowed for an overall reduction in CT scans. Part of the control phase is monitoring for outlier providers who may need individual education to further reduce variability.

Discussing the project with providers after implementation revealed that, while another pop-up box and mandatory form is not ideal, it had minimal impact on the workflow during clinical shifts. There have been other ideas about how to use the PowerForm to fill the mandatory fields describing the 'Reason for Exam' section of the CT C-spine order. However, this was not able to be completed during the project. This is an area of potential 


\section{Number of CT C-Spine Orders/Week}

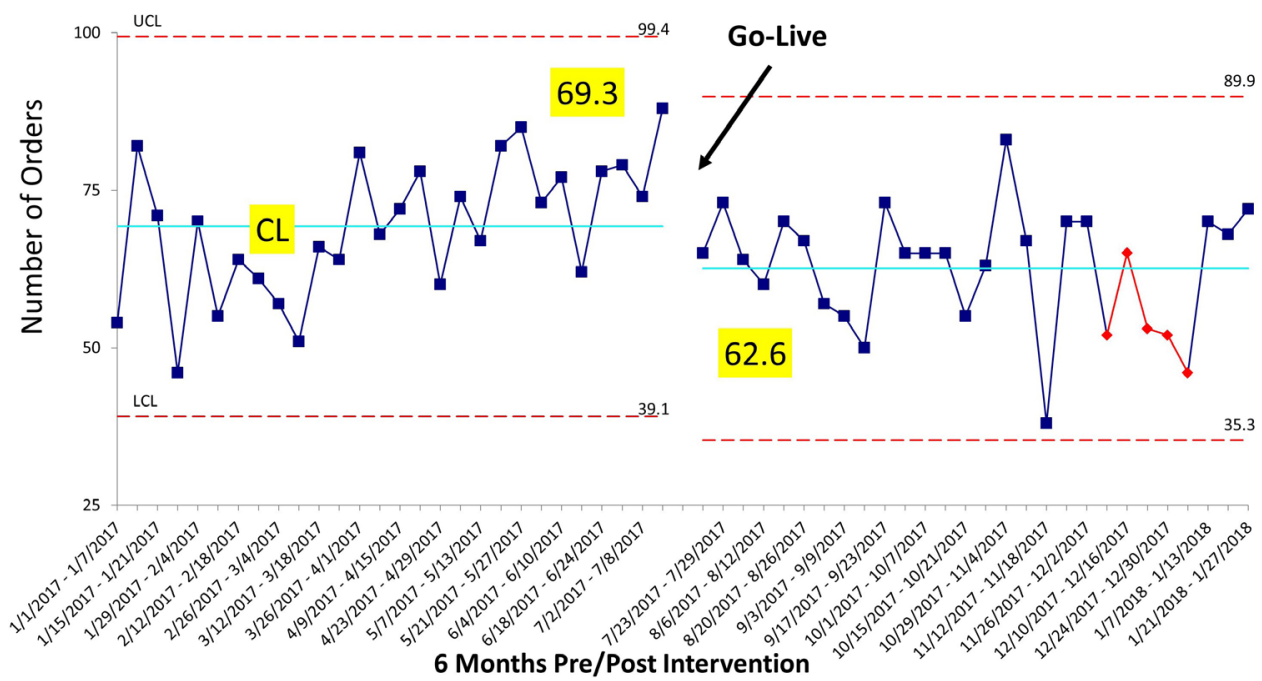

Figure 3 Number of CT C-spine scans ordered per week decreased from 69.3 to 62.6 after implementation of the PowerForm. Two sample t-test, $\mathrm{p}=0.019$.

future improvement to not only use the PowerForm to improve the medical appropriateness of the orders but also to assist physicians in the workflow of the clinical shift.

Impact of the interventions was similar to previous studies. Stiell et $a l^{36}$ reported a $12.8 \%$ reduction in imaging studies for hospitals that implemented Canadian C-Spine Rules on radiology requisitions. Goergen et $a l^{37}$ reported a $9.7 \%$ decrease in C-spine studies, with $36 \%$ of studies not meeting criteria for imaging after implementation of pocket card reminders with the guidelines, teaching sessions and optional use of computerised decision support software. After implementation of education and a NEXUS-based PowerForm, this study found a $9.7 \%$ decrease in C-spine studies, with $22 \%$ not meeting criteria for imaging.

\section{LESSONS AND LIMITATIONS}

The analysis after the interventions were implemented was completed in a different manner than the analysis prior to the intervention. Chart reviews allow for more clinical insight rather than the assumption that all orders that had the 'other' option selected in the PowerForm are medically inappropriate because they did not conform with the decision rule. Without a post-intervention chart review, it is unknown whether the percent of medically appropriate orders would be changed by this 'yes/no' dichotomy. The intervention was based on the NEXUS criteria. The ACR gives a level 9 qualification for both the NEXUS criteria and the Canadian C-Spine Rule. The Canadian C-Spine Rule has been well validated. Numerous studies have compared the NEXUS criteria to the Canadian C-Spine Rule with mixed results. The NEXUS criteria were used in the PowerForm due to the simplicity of the criteria and the ability to translate this into a user-friendly selection list. There may be providers following the Canadian C-Spine Rule who had their orders deemed medically inappropriate. Both of these limitations may actually improve the data if additional chart reviews are completed.

Another limitation is that this study was performed only at one medical centre. Our institution has a robust quality improvement team and the implementation and maintenance of the PowerForm was not overly burdensome. The electronic medical record also allowed for easy implementation. This study design may need significant modification if implemented at a medical centre with different order processes and electronic medical records. Lack of formal evaluation of the educational approach is a potential limitation of the study.

Implications of this study for other areas of medicine are important to discuss. A well-validated clinical decisionmaking tool was able to be implemented into the medical chart. This generated a statistically significant decrease in CT utilisation. The study was designed as a potential template for other types of CT scans to be evaluated and potentially improved as CT of the cervical spine is not the only area of opportunity for improvement. The results of this study may carry over to other clinical decisions that have validated clinical decision-making tools. One area that may be of particular interest would be applying this study design to pediatric head trauma. The Pediatric Emergency Care Applied Research Network (PECARN) head trauma criteria could easily be written into a PowerForm, potentially having a clinically significant reduction in CT scans in a pediatric patient population. ${ }^{46}$ The methods of this study lend themselves to replication on any area of focus that has validated clinical decision tools. While CT of the cervical spine is only a small portion of the overall CT utilisation, any reduction in the overall 
number of scans is an important improvement. If several studies are successful, a more significant impact may be reached on reducing the total number of CT scans.

\section{CONCLUSION}

A validated clinical decision-making tool implemented into the medical record assisted in reducing medically inappropriate CT C-spine scans, decreased variability between ordering providers and decreased the total number of CT C-spine scans ordered. The PowerForm allows for long-term monitoring of results from the intervention in the control phase. Different diagnostic imaging studies may achieve similar improvements by applying this study model, further reducing the continued overall high CT utilisation rate.

Contributors MB contributed to the study concept and design, acquisition of data and drafting of the manuscript. CJ contributed to analysis of data, drafting of the manuscript and critical revision of the manuscript. $\mathrm{CH}$ contributed to the study concept and design, acquisition of data and study supervision. JW contributed to study concept and design, critical revision of the manuscript and study supervision.

Funding The authors have not declared a specific grant for this research from any funding agency in the public, commercial or not-for-profit sectors.

Competing interests None declared.

Patient and public involvement Patients and/or the public were not involved in the design, or conduct, or reporting or dissemination plans of this research.

Patient consent for publication Not required.

Provenance and peer review Not commissioned; externally peer reviewed.

Data availability statement № data are available.

Open access This is an open access article distributed in accordance with the Creative Commons Attribution Non Commercial (CC BY-NC 4.0) license, which permits others to distribute, remix, adapt, build upon this work non-commercially, and license their derivative works on different terms, provided the original work is properly cited, appropriate credit is given, any changes made indicated, and the use is non-commercial. See: http://creativecommons.org/licenses/by-nc/4.0/.

ORCID iD

Cassie Jaeger http://orcid.org/0000-0002-2726-6867

\section{REFERENCES}

1 Kirsch TD, Hsieh Y-H, Horana L, et al. Computed tomography scan utilization in emergency departments: a multi-state analysis. J Emerg Med 2011;41:302-9.

2 Levine MB, Moore AB, Franck C, et al. Variation in use of all types of computed tomography by emergency physicians. Am J Emerg Med 2013;31:1437-42.

3 Dick EA, Varma D, Kashef E, et al. Use of advanced imaging techniques during visits to emergency departments--implications, costs, patient benefits/risks. Br J Radiol 2016;89:20150819.

4 Kocher KE, Meurer WJ, Desmond JS, et al. Effect of testing and treatment on emergency department length of stay using a national database. Acad Emerg Med 2012;19:525-34.

5 McCarthy ML, Zeger SL, Ding R, et al. Crowding delays treatment and lengthens emergency department length of stay, even among high-acuity patients. Ann Emerg Med 2009;54:492-503.

6 National Council on Radiation Protection and Measurements. Ionizing radiation exposure of the population of the United States. NCRP report 160. Bethesda, MD: National Council on Radiation Protection and Measurements, 2009.

7 Radiation dose of CT scan (Australian radiation protection and nuclear safety agency, radiation protection series no 14.1 , radiation protection in diagnostic and interventional radiology, 2008

8 Preston DL, Ron E, Tokuoka S, et al. Solid cancer incidence in atomic bomb survivors: 1958-1998. Radiat Res 2007;168:1-64.

9 Cardis E, Vrijheid M, Blettner M, et al. The 15-Country collaborative study of cancer risk among radiation workers in the nuclear industry: estimates of radiation-related cancer risks. Radiat Res 2007;167:396-416

10 Wolfson D, Santa J, Slass L. Engaging physicians and consumers in conversations about treatment overuse and waste: a short history of the choosing wisely campaign. Acad Med 2014;89:990-5.

11 Maughan BC, Baren JM, Shea JA, et al. Choosing wisely in emergency medicine: a national survey of emergency medicine academic chairs and division chiefs. Acad Emerg Med 2015;22:1506-10.

12 Klauer K. Emergency physicians should put choosing wisely recommendations into action. ACEP Now, 2016. Available: https:// www.acepnow.com/article/emergency-physicians-should-putchoosing-wisely-recommendations-into-action/?singlepage $=1$ [Accessed 7 Sep 2018].

13 Malik SA, Murphy M, Connolly P, et al. Evaluation of morbidity, mortality and outcome following cervical spine injuries in elderly patients. Eur Spine J 2008;17:585-91.

14 Milby $\mathrm{AH}$, Halpern $\mathrm{CH}$, Guo W, et al. Prevalence of cervical spinal injury in trauma. Neurosurg Focus 2008;25:E10.

15 Conneely M, Park J, Demos TC. Radiologic case study. cervical spine trauma: unstable fractures, $\mathrm{C} 2-\mathrm{C} 7$ injuries, and imaging guidelines. Orthopedics 2008;31:818.

16 Hoffman JR, Wolfson AB, Todd K, et al. Selective cervical spine radiography in blunt trauma: methodology of the National emergency X-Radiography utilization study (nexus). Ann Emerg Med 1998;32:461-9.

17 Lapinsky A, Eskander M. Clearing cervical spine injuries: MRI, dynamic x-rays, CT, 2018. Available: http://www.thieme.com/media/ samples/pubid1233003906.pdf [Accessed 7 Sep 2018].

18 Griffiths HJ, Wagner J, Anglen J, et al. The use of forced flexion/ extension views in the obtunded trauma patient. Skeletal Radiol 2002;31:587-91.

19 Anglen J, Metzler M, Bunn P, et al. Flexion and extension views are not cost-effective in a cervical spine clearance protocol for obtunded trauma patients. J Trauma 2002;52:54-9.

20 Schuster R, Waxman K, Sanchez B, et al. Magnetic resonance imaging is not needed to clear cervical spines in blunt trauma patients with normal computed tomographic results and no motor deficits. Arch Surg 2005;140:762-6.

21 Cooper DJ, Ackland HM. Clearing the cervical spine in unconscious head injured patients - the evidence. Crit Care Resusc 2005;7:181-4.

22 Benzel EC, Hart BL, Ball PA, et al. Magnetic resonance imaging for the evaluation of patients with occult cervical spine injury. $J$ Neurosurg 1996;85:824-9.

23 Muchow RD, Resnick DK, Abdel MP, et al. Magnetic resonance imaging (MRI) in the clearance of the cervical spine in blunt trauma: a meta-analysis. J Trauma 2008;64:179-89.

24 Michaleff ZA, Maher CG, Verhagen AP, et al. Accuracy of the Canadian C-spine rule and NEXUS to screen for clinically important cervical spine injury in patients following blunt trauma: a systematic review. CMAJ 2012;184:E867-76.

25 Tran J, Jeanmonod D, Agresti D, et al. Prospective validation of modified NEXUS cervical spine injury criteria in low-risk elderly fall patients. West J Emerg Med 2016;17:252-7.

26 Touger M, Gennis P, Nathanson N, et al. Validity of a decision rule to reduce cervical spine radiography in elderly patients with blunt trauma. Ann Emerg Med 2002;40:287-93.

27 Evans D, Vera L, Jeanmonod D, et al. Application of national emergency X-ray utilizations study low-risk C-spine criteria in highrisk geriatric falls. Am J Emerg Med 2015;33:1184-7.

28 Stiell IG, Wells GA, Vandemheen KL, et al. The Canadian C-spine rule for radiography in alert and stable trauma patients. JAMA 2001;286:1841-8.

29 American College of Radiology. ACR appropriate criteria: suspected spine trauma, 2018. Available: https://acsearch.acr.org/docs/69359/ Narrative/ [Accessed 7 Sep 2018].

30 Congress.Gov. H.R. 4302 - protecting access to Medicare act of 2014. 113th Congress (2013 - 2014), 2018. Available: https://www. congress.gov/bill/113th-congress/house-bill/4302 [Accessed 7 Sep 2018].

31 Griffith B, Bolton C, Goyal N, et al. Screening cervical spine CT in a level I trauma center: overutilization? AJR Am J Roentgenol 2011;197:463-7.

32 Griffith B, Kelly M, Vallee P, et al. Screening cervical spine CT in the emergency department, phase 2: a prospective assessment of use. AJNR Am J Neuroradiol 2013;34:899-903.

33 Griffith B, Vallee P, Krupp S, et al. Screening cervical spine CT in the emergency department, phase 3: increasing effectiveness of imaging. J Am Coll Radiol 2014;11:139-44.

34 Uriell ML, Allen JW, Lovasik BP, et al. Yield of computed tomography of the cervical spine in cases of simple assault. Injury 2017;48:133-6. 
35 Desai S, Liu C, Kirkland SW, et al. Effectiveness of implementing Evidence-based interventions to reduce $\mathrm{C}$-spine image ordering in the emergency department: a systematic review. Acad Emerg Med 2018;25:672-83.

36 Stiell IG, Clement CM, Grimshaw J, et al. Implementation of the Canadian C-spine rule: prospective 12 centre cluster randomised trial. BMJ 2009;339:b4146.

37 Goergen SK, Fong C, Dalziel K, et al. Can an evidence-based guideline reduce unnecessary imaging of road trauma patients with cervical spine injury in the emergency department? Australas Radiol 2006;50:563-9.

38 Slater R. Jack Welch and the GE way: management insights and leadership secrets of the legendary CEO. New York, NY: McGrawHill, 1999.

39 Womack J, Jones D, Roos D. The machine that changed the world. New York, NY: Rawson Associates, 1990.

40 Liker J. The Toyota way: 14 management principles from the world's greatest manufacturer. New York: NY: McGraw-Hill, 2004.
41 George M. Lean six sigma for service. New York, NY: McGraw-Hill, 2003.

42 van Leijen-Zeelenberg JE, Elissen AMJ, Grube K, et al. The impact of redesigning care processes on quality of care: a systematic review. BMC Health Serv Res 2016;16:19.

43 Schweikhart SA, Dembe AE. The applicability of lean and six sigma techniques to clinical and translational research. $J$ Investig Med 2009;57:748-55.

44 Johnson PM, Patterson CJ, O'Connell MP. Lean methodology: an evidence-based practice approach for healthcare improvement. Nurse Pract 2013;38:1-7.

45 Ahmed S, Manaf NHA, Islam R. Effects of lean six sigma application in healthcare services: a literature review. Rev Environ Health 2013;28:189-94.

46 Kuppermann N, Holmes JF, Dayan PS, et al. Identification of children at very low risk of clinically-important brain injuries after head trauma: a prospective cohort study. Lancet 2009;374:1160-70. 